\title{
DÁ PRA FAZER - PROBLEMATIZAÇÕES ACERCA DE ASPECTOS DA TEMÁTICA TRABALHO E EDUCAÇÃO ESCOLAR PARA PESSOAS COM DIVERSIDADE FUNCIONAL INTELECTUAL
}

\section{Si può fare - Problematisation about aspects of the topics working and school education for people with intellectual functional diversity}

Agnes Iara Domingos Moraes

Faculdade de Filosofia e Ciências, UNESP - Univ. Estadual Paulista, Brasil

Correo-e: moraes.aid@gmail.com

Cláudio Rodrigues da SiLva

Faculdade de Filosofia e Ciências, UNESP - Univ. Estadual Paulista, Brasil

Correo-e: silvanegrao@gmail.com

Recepción: 26 de enero de 2018

Envío a informantes: I3 de febrero de 2018

Aceptación definitiva: $\mathrm{I}$ de diciembre de 2018

Resumo: Neste texto tem-se por objetivo apresentar, a partir do filme Dá pra fazer (2008), uma problematização - com aporte de bibliografia e documentos relacionados à temática - acerca da questão do trabalho e da educação escolar para pessoas com diversidade funcional intelectual. A relação entre trabalho e educação é um tema que perpassa a história de alguns dos principais movimentos sociais de trabalhadores desde o momento histórico da Revolução Industrial até a atualidade. No Brasil, políticas inclusivas focadas em pessoas com diversidade funcional intelectual ganham ênfase a partir das duas últimas décadas do século xx, quando, além de garantias legais, são implementadas medidas visando à inclusão de pessoas com diversidad funcional na educação escolar e no mercado de trabalho, questões essas, em alguma medida, inter-relacionadas.

Palavras-Chave: educação e trabalho; educação inclusiva; história da educação; diversidade funcional intelectual; saúde mental; autoeducação. 
DÁ PRA FAZER - PROBLEMATIZAÇÕES ACERCA DE ASPECTOS DA TEMÁTICA TRABALHO E EDUCAÇÃO ESCOLAR PARA PESSOAS COM DIVERSIDADE FUNCIONAL INTELECTUAL AGNES IARA DOMINGOS MORAES Y CLÁUDIO RODRIGUES DA SILVA

AвstRAct: Stem from the film Si Può Fare (2008), this paper aims to present a problematisation - with a bibliographic support and topic related documents - about the work and school education issue for people with intellectual functional diversity. The relation between work and education is a topic that passes by the history of some of the most important social movements of workers from the Industrial Revolution until current days. In Brazil, the inclusive policies focused on people with intellectual functional diversity win emphasis as of the last two decades of the xx century, when, in addition to the legal guarantee, some measures are implemented, aiming to include people with functional diversity in school education and work market. These issues are somehow interconnected.

KEY WORDS: education and work; inclusive education; history of education; intellectual functional diversity; mental health; self-education.

I.

$\mathrm{N}$ ESTE TEXTO, tem-se por objetivo apresentar, com aporte de bibliografia e documentos relacionados à temática, problematização sobre a questão do trabalho e da educação escolar para pessoas com diversidade funcional intelectual, tomando como ponto de partida o filme intitulado Dá pra fazer (2008).

A relação entre trabalho e educação é um tema que perpassa a história de alguns dos principais movimentos sociais de trabalhadores - como, por exemplo, anarquistas, cartistas britânicos, socialistas utópicos owenistas e marxistas - desde o momento histórico da Revolução Industrial (Chauveau, I998; Manacorda, I992; Silva, 2014) até a atualidade.

No Brasil, políticas públicas focais para pessoas com diversidade funcional intelectual ganham ênfase a partir das duas últimas décadas do século xx, quando, além de garantias constantes na legislação, com destaque para a Constituição Federal (Brasil, 1988) e para a Lei de Diretrizes e Bases da Educação Nacional (Brasil, 1996), são implementadas medidas visando à inclusão de pessoas com diversidad funcional na educação escolar e no mercado de trabalho (Freitas, 20I4; Oliveira, 2008). Assim, trata-se de uma temática relevante e atual. A arte e suas diferentes linguagens, entre elas, o cinema, apresentam-se como importante fator educativo, inclusive no que se refere a mediações no processo de ensino-e-aprendizagem (Santos e Noro, 2013).

Ainda que, no Brasil, Deficiência Intelectual predomine na bibliografia específica e seja a categoria utilizada na legislação federal, opta-se, neste texto, por utilizar a categoria diversidad funcional, dadas as implicações teórico-práticas subjacentes a essas diferentes categorias.

Diversidad funcional é uma categoria retomada pelo Foro de Vida Independiente. Segundo Romañach e Lobato (2005: 5),

El término mujeres y hombres con diversidad funcional es novedoso y se propuso y empezó a utilizar en el Foro de Vida Independiente en enero de 2005. Entendemos que es la primera vez en la historia y en el mundo que se propone un cambio hacia una terminología no negativa sobre la diversidad funcional, y que esa propuesta parte exclusivamente de las mujeres y hombres con diversidad funcional. Pretendemos ir incluso más allá y obviar la estrategia social del 'desviacionismo', esa que obtiene como resultados el 'ellos' y 'nosotros', para plantear que la diversidad funcional es algo inherente al ser humano 
DÁ PRA FAZER - PROBLEMATIZAÇÕES ACERCA DE ASPECTOS DA TEMÁTICA TRABALHO E EDUCAÇÃO ESCOLAR PARA PESSOAS COM DIVERSIDADE FUNCIONAL INTELECTUAL AGNES IARA DOMINGOS MORAES Y CLÁUDIO RODRIGUES DA SILVA

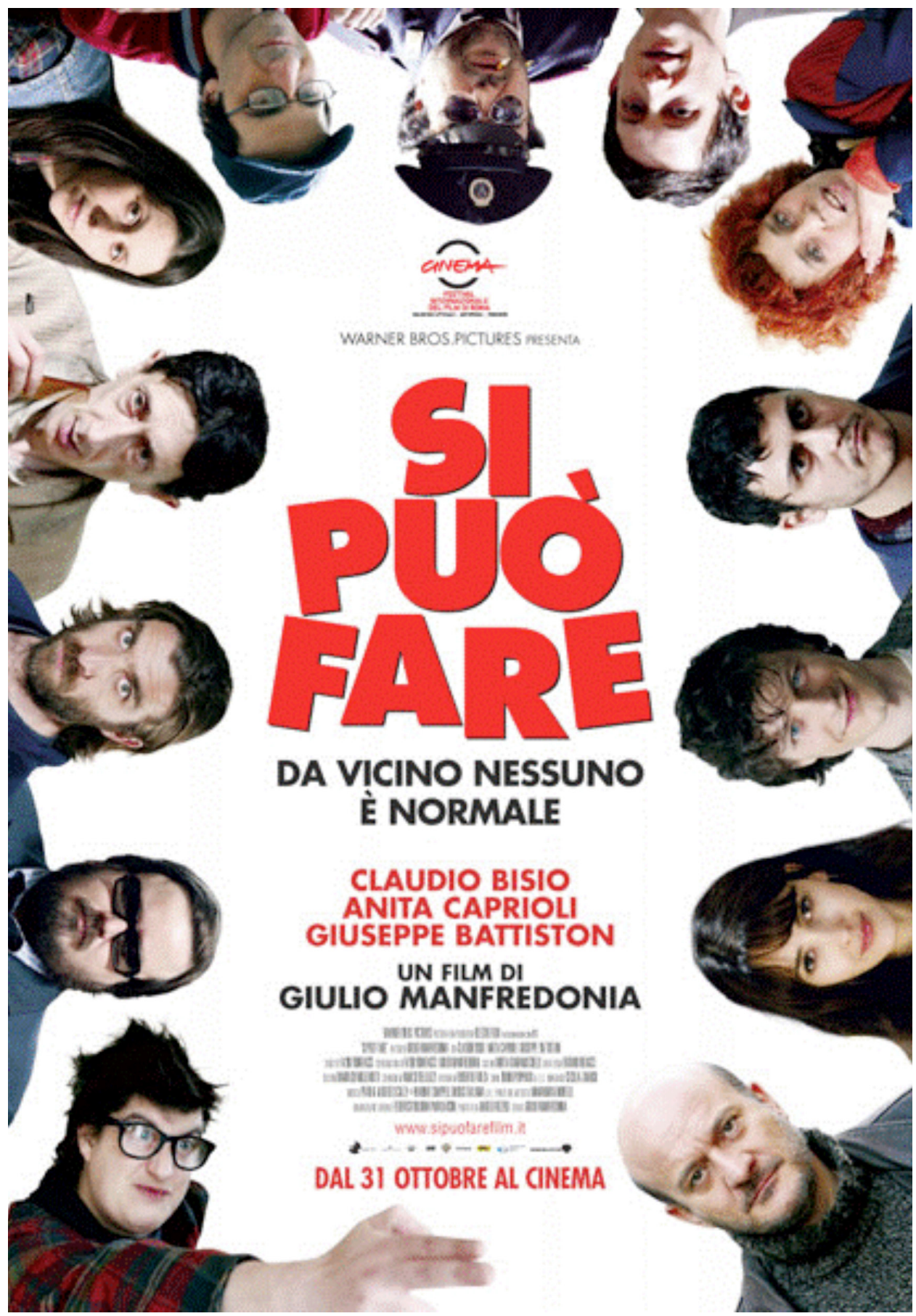

Figura i. Filme Dá pra fazer (2008). 
DÁ PRA FAZER - PROBLEMATIZAÇÕES ACERCA DE ASPECTOS DA TEMÁTICA TRABALHO E EDUCAÇÃO ESCOLAR PARA PESSOAS COM DIVERSIDADE FUNCIONAL INTELECTUAL AGNES IARA DOMINGOS MORAES Y CLÁUDIO RODRIGUES DA SILVA

y que, en muchas ocasiones, puede ser de carácter transitorio o circunstancial, por lo que aflora su carácter de conflicto social que de forma directa, indirecta, transitoria o definitiva, a todos nos alcanza.

Ressalta-se que assim como outras categorias, diversidad funcional não está isenta de contradições ou críticas (Rodríguez Díaz e Vázquez Ferreira, 20ıo).

Dentre os segmentos que compõem o grupo denominado Estudantes Público-alvo da Educação Especial, enfatiza-se principalmente a diversidade funcional intelectual, haja vista que, por diversas razões, é o segmento mais polêmico, em se tratando da educação escolar, especialmente no que se refere a adequações curriculares (Oliveira, 2008; Pletsch, 20Io). Destaca-se que diversidade funcional intelectual é uma categoria ampla e utilizada para fazer menção a uma significativa variedade de casos com especificidades e necessidades intelectuais comuns e também diferenciadas entre si, não cabendo, portanto, homogeneização das pessoas enquadradas nessa categoria.

\section{2.}

O filme Dá pra fazer, cujo o título original é Se può fare, trata-se de uma produção italiana de ııo minutos, dirigida por Giulio Manfredonia e lançada em 2008.

Esse filme aborda a questão das cooperativas de trabalho social na Itália, na década de 1980 , em consonância com a Lei n. ${ }^{\circ}$ I80, que trata da Reforma Psiquiátrica na Itália e que é também conhecida como Lei Basaglia, em referência a Franco Basaglia (I924I980), precursor das lutas antimanicomiais ${ }^{1}$.

No contexto da reforma do sistema de saúde mental da Itália, realizada no final dos anos [19]70, a partir da Lei Basaglia que aboliu os hospitais psiquiátricos, iniciou-se um rico e inovador processo de incentivo à criação de cooperativas para inclusão produtiva dos usuários de serviços de saúde mental. Estes empreendimentos foram definidos por lei como 'Cooperativas Sociais'. A partir dos anos 80 mais de 3 mil destas cooperativas foram criadas na Itália (Marques, 2010: 9).

No entendimento de Sade (2017: 7)

Na Itália o fim do hospital psiquiátrico foi o ponto de chegada e não de partida. Enquanto Países como Inglaterra e França tentavam fazer suas reformas sob uma perspectiva de reorganização modernizadora, criando serviços psiquiátricos alternativos, articulados aos hospitais, na Itália o movimento iniciado por Franco Basaglia, promoveu transformação na assistência e na política de saúde, substituiu o hospital psiquiátrico por uma rede de serviços no território: atenção à crise, moradia, reabilitação, cooperativas sociais, centros para tóxico-dependências, ambulatórios e outros.

Dá pra fazer instiga e permite abordagens de variados assuntos, a partir de diferentes perspectivas teóricas, áreas ou subáreas do conhecimento. Neste texto, porém,

Basaglia foi, segundo Marques (20I0: IO), «[...] o psiquiatra que promoveu a reforma no sistema de saúde mental italiano. Como diretor do Serviço Hospitalar de Trieste, Basaglia implantou reformas que foram consideradas pela Organização Mundial da Saúde (омs) como referência mundial para reformulação da assistência à saúde mental. A partir desta experiência foi aprovada em 1978 a chamada 'Lei Basaglia' que estabeleceu a reforma do sistema que teve como uma das principais medidas a abolição dos hospitais psiquiátricos na Itália». 
DÁ PRA FAZER - PROBLEMATIZAÇÕES ACERCA DE ASPECTOS DA TEMÁTICA TRABALHO E EDUCAÇÃO ESCOLAR PARA PESSOAS COM DIVERSIDADE FUNCIONAL INTELECTUAL AGNES IARA DOMINGOS MORAES Y CLÁUDIO RODRIGUES DA SILVA

tem-se como objetivo abordar a questão do trabalho e da educação, estabelecendo-se algumas relações entre esses dois quesitos no que se refere a pessoas com diversidade funcional intelectual ${ }^{2}$ no Brasil, cuja legislação (Brasil, I99ı, 2008) estabelece mecanismos para promover a denominada inclusão social de pessoas com diversidade funcional intelectual, bem como de pessoas com outras diversidades funcionais, em diferentes áreas sociais, em especial no mercado de trabalho e na educação escolar.

Conforme Marques (2010: 9),

O filme conta a história de uma das primeiras experiências de cooperativas sociais criadas nos anos [19]8 o na Itália. O protagonista é Nello, um sindicalista que é convidado a coordenar uma cooperativa formada pelos ex-pacientes dos manicômios fechados pela Lei Basaglia. Acreditando no trabalho, Nello se envolve profundamente com a tarefa de auxiliar na organização do empreendimento em uma perspectiva de inclusão produtiva e não assistencial.

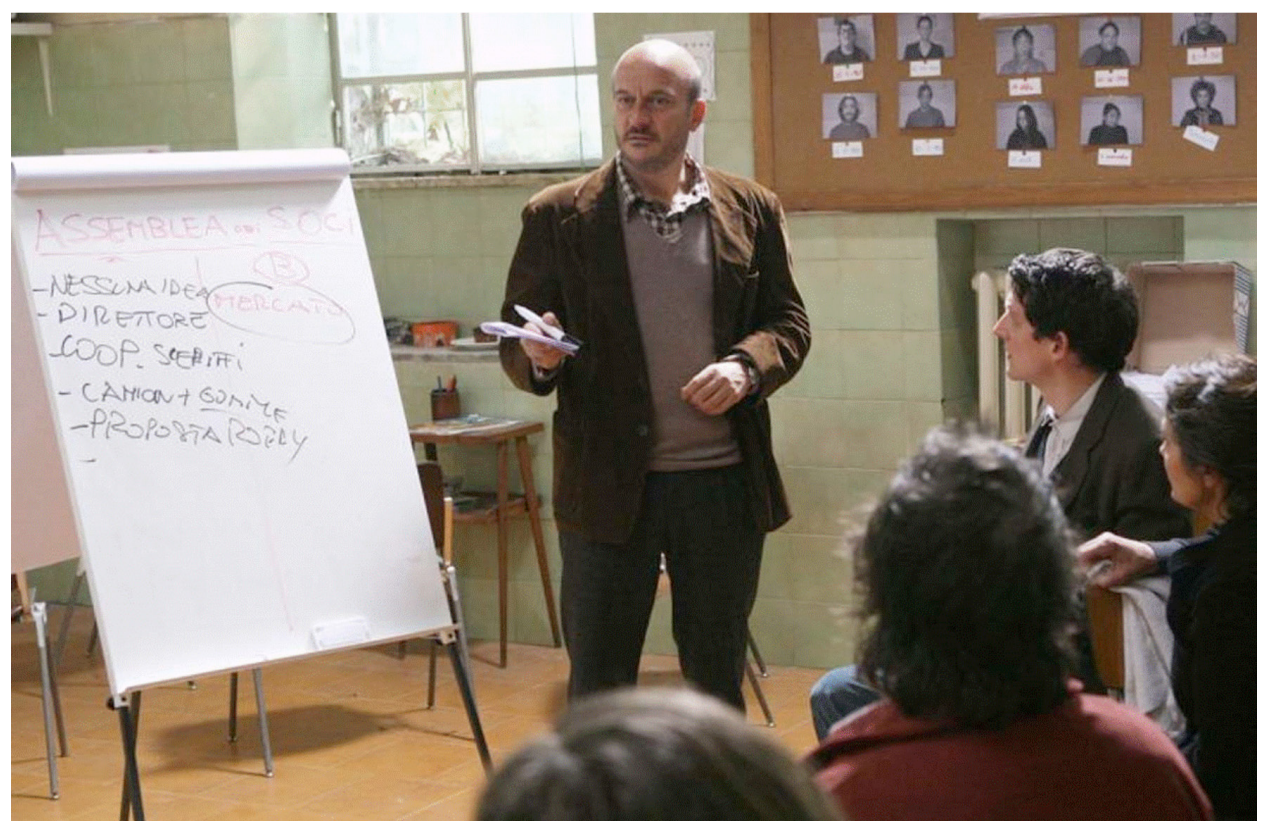

Figura 2. Nello coordenando a primeira assembleia dos sócios da «Cooperativa 180».

Ao assumir o cargo de diretor da «Cooperativa ı8o» - o nome da Cooperativa parece estabelecer alguma relação com o número da lei que trata da Reforma Psiquiátrica na Itália -, Nello encontra os então pacientes realizando trabalhos numa perspectiva assistencialista. Eram trabalhos repetitivos, com pouco ou nenhum reconhecimento social e aparentemente sem sentido para quem os executava. Os trabalhos realizados pareciam ter como objetivo maior manter os pacientes ocupados e disciplinados.

O filme em tela faz referência a pessoas em situação de tratamento relacionado à saúde mental. Todavia, ainda que, em dados casos, possa haver concomitância, não há relações necessárias entre diversidade funcional intelectual e problemas de saúde mental. 


\section{E EDUCAÇÃO ESCOLAR PARA PESSOAS COM DIVERSIDADE FUNCIONAL INTELECTUAL AGNES IARA DOMINGOS MORAES Y CLÁUDIO RODRIGUES DA SILVA}

Os trabalhadores, além de fortemente medicados para serem mantidos sob controle, eram tratados como infantes, ou seja, sem direito à voz e à decisão, inclusive no que se refere a aspectos básicos das próprias vidas, estando, assim, submetidos à incondicional tutela do «Doutor Del Vecchio», médico responsável pelos pacientes da «Cooperativa I8o» e que decidia unilateralmente todas as questões que diziam respeito à vida dessas pessoas. Em outras palavras, os trabalhadores estavam em situação de total alienação em todas as áreas da vida, em especial no trabalho.

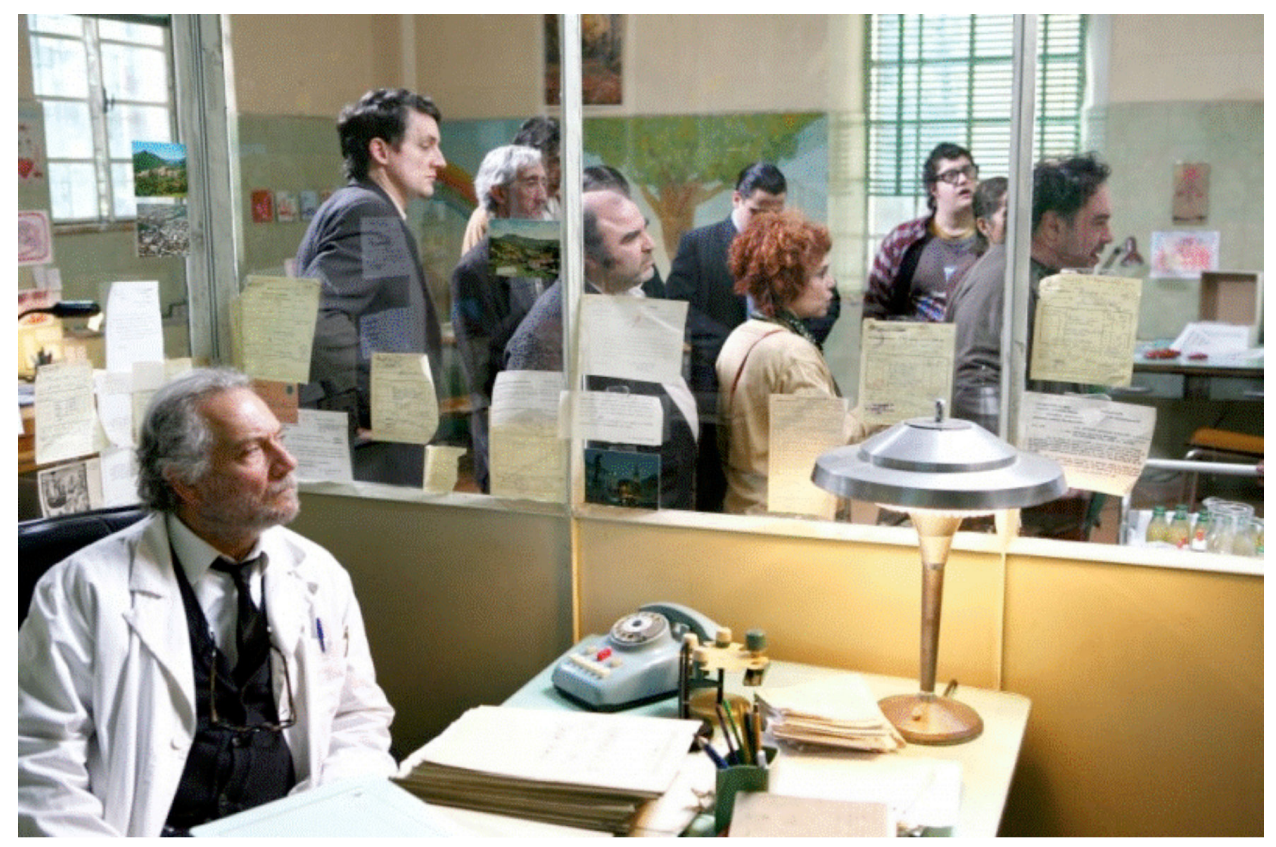

Figura 3. Doutor Del Vecchio em seu escritório: só observando...

Assim que assume esse cargo, Nello, não sem dificuldades e contradições, esforça-se para inverter a lógica das relações sociais existentes na Cooperativa. Ele procura conhecer as histórias de vida de cada cooperado. Procura, ainda, romper com as relações hierárquico-verticais, passando a incentivar a participação ativa e o exercício do direito à voz e a voto dos trabalhadores, conforme as respectivas condições - objetivas ou subjetivas, individuais ou coletivas - daquele momento.

Nello promove uma assembleia e coloca em pauta as seguintes alternativas: ou «trabalhos assistenciais» ou «entrar no mercado». A maioria dos sócios decide pela segunda opção.

Dessa forma, de pacientes (passivos) eles passam à condição de sócios (ativos), realizando trabalho efetivamente produtivo ${ }^{3}$, com valor e reconhecimento sociais: passaram a ser profissionais de instalação de parquet. Eles são colocados em situação de

Neste texto, trabalho produtivo não tem relações com o debate marxista sobre trabalho produtivo e trabalho improdutivo, mas, faz referência a trabalhos reais, visando à participação na economia real ou, em palavras de Nello, «entrar no mercado». 


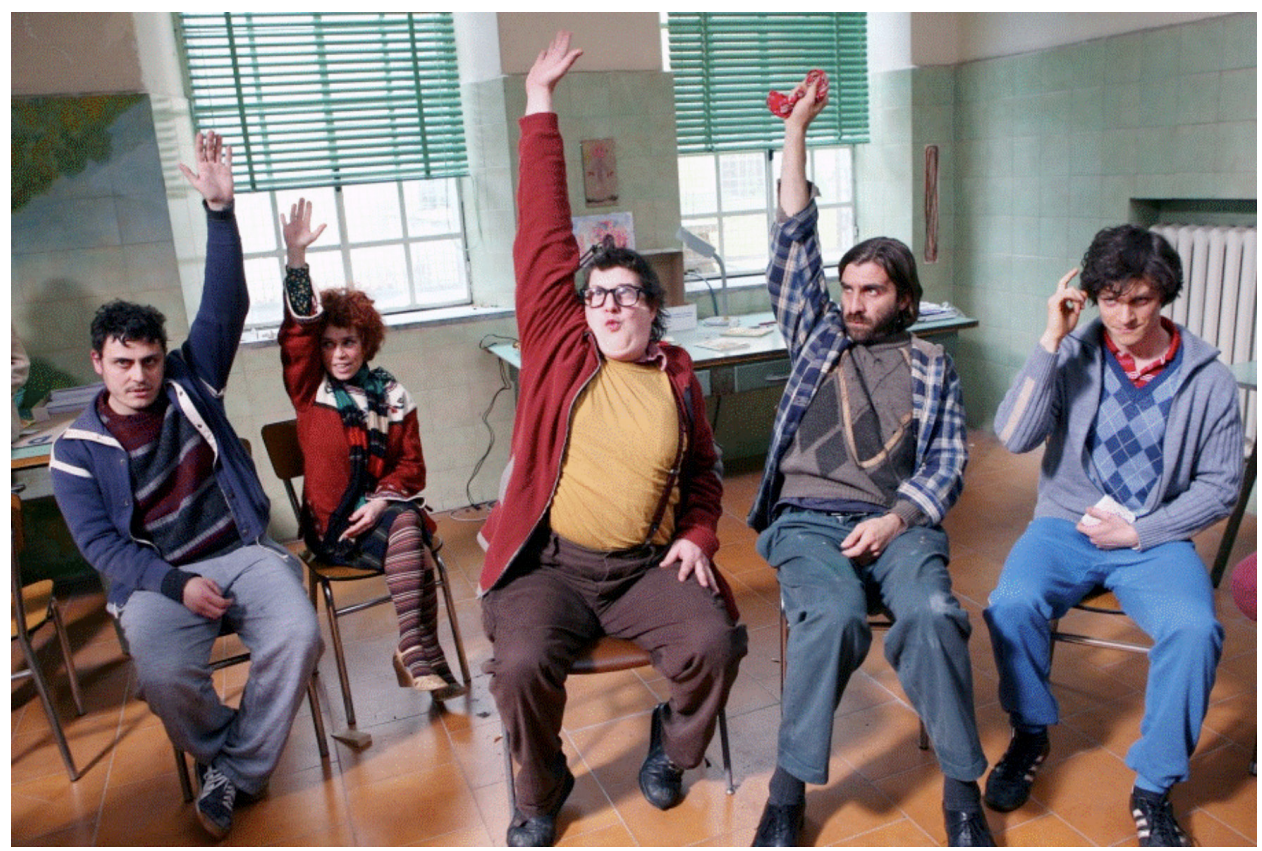

Figura 4. Momento da assembleia dos sócios da «Cooperativa 180»: direito à voz e a voto.

igualdade real, em especial no que tange ao direito à voz e a voto, bem como no que se refere à remuneração pelo trabalho realizado. No entanto, isso implicava assumir não só os bônus, mas também os ônus inerentes a essa nova condição, desafio esse enfrentado coletivamente.

Auxiliá-los, isto é, realizar mediações visando contribuir para o processo de saída da condição de alienação e de heteronomia rumo a uma relação de progressivas autonomia e responsabilidade pelos próprios atos e decisões foi um dos maiores desafios enfrentados por Nello, já que essa mudança demandou um processo de reeducação - inclusive do próprio Nello, que teve que aprender a lidar com diversas situações de discordâncias ou recusas dos sócios -, pois eles, que ficaram diversos anos na condição de pacientes, precisaram, de um momento para outro, passar à condição de sujeitos no processo de decisão sobre as diversas questões atinentes às próprias vidas, seja na dimensão individual seja na coletiva.

Tanto Nello quanto os sócios tiveram que se (auto) reeducar na e para outra perspectiva de sociabilidade, que envolve, simultaneamente, autonomia, independência, debates, conflitos, enfim, na e para a participação ativa, tomando decisões e assumindo as responsabilidades por elas. Esse processo teve relações diretas e indiretas com autoimagem, autoestima, autoconfiança dos sócios, entre outros aspectos.

Um dos pontos que se destaca neste texto é a falta de formação ou de capacitação técnica ou profissional para o trabalho produtivo. Isso parece ter sido um quesito dificultador no processo de empoderamento e de emancipação dos cooperados, até porque essa perspectiva não estava entre os objetivos do «Doutor Del Vecchio», médico responsável pela Cooperativa. 
DÁ PRA FAZER - PROBLEMATIZAÇÕES ACERCA DE ASPECTOS DA TEMÁTICA TRABALHO E EDUCAÇÃO ESCOLAR PARA PESSOAS COM DIVERSIDADE FUNCIONAL INTELECTUAL AGNES IARA DOMINGOS MORAES Y CLÁUDIO RODRIGUES DA SILVA

3.

A questão da educação e do trabalho tem implicações diretas para a qualidade de vida das pessoas com diversidade funcional intelectual, pois são duas áreas fundamentais para uma vida autônoma e independente. Segundo Schalock e Verdugo (2007: 22) «Calidad de vida es un estado deseado de bienestar personal que: (a) es multidimensional; (b) tiene propiedades éticas - universales-y emicas -ligadas a la cultura; (c) tiene componentes objetivos y subjetivos; $y(d)$ esta influenciada por factores personales y ambientales».

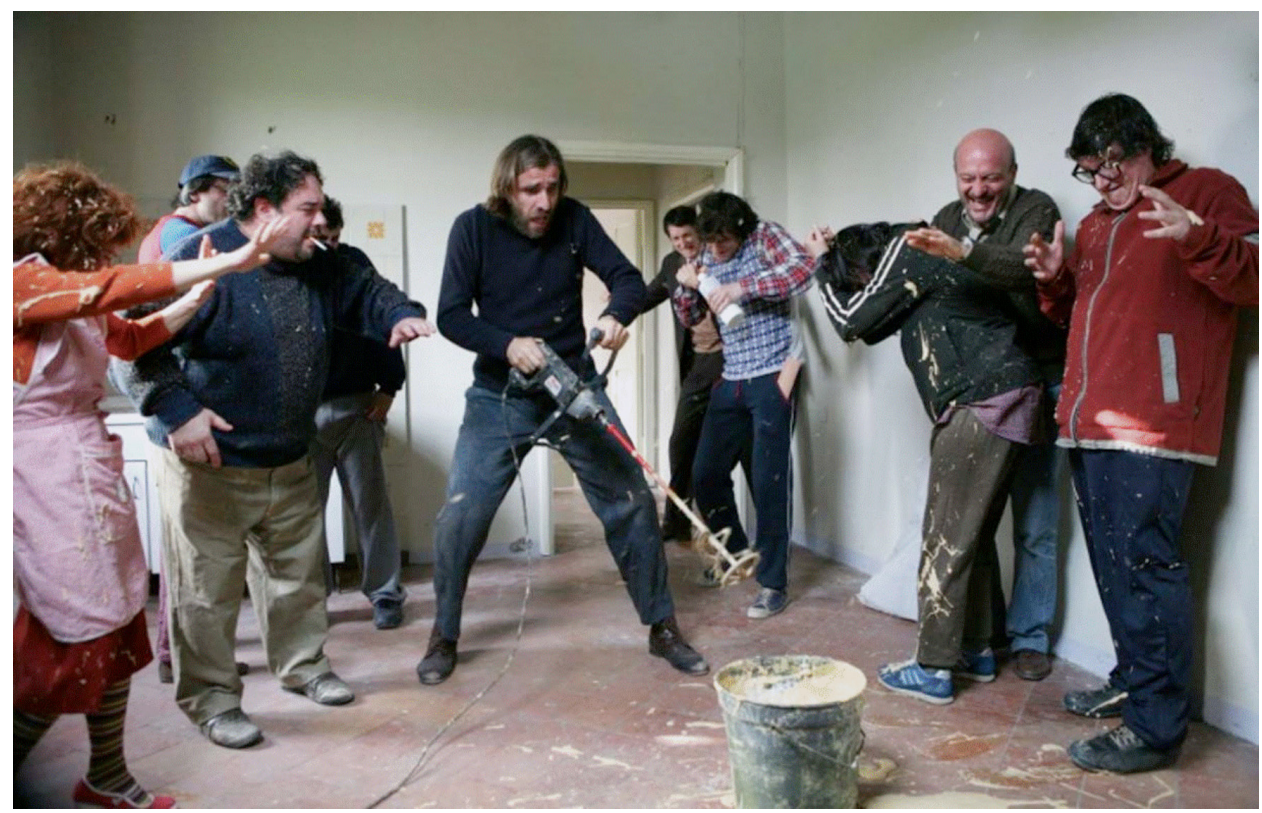

FigurA 5. Trabalhando e aprendendo: agora eles são profissionais em instalação de parquet.

Outro ponto que se destaca é a questão da aparente falta ou do baixo nível de domínio dos conhecimentos escolares pela maioria dos sócios. Essa condição resultava em impactos negativos em variadas áreas da vida dos sócios. Fábio (Pietro Ragusa) destacava-se em dados aspetos pelo domínio desses conhecimentos e era uma espécie de contador, em condição, em termos, privilegiada, e que colocava os sócios em situação de relativa dependência dele, relação essa que, se não devidamente mediada, poderia ser transformada num fator de hierarquização vertical entre os sócios.

No processo de transformação levado a termo na "Cooperativa I80", os sócios, especialmente Nello, encontraram diversos desafios, em especial barreiras sociais decorrentes de preconceitos em relação à condição de saúde mental dos cooperados. Contudo, na maioria das vezes Nello soube lidar, não sem contradições, de forma relativamente hábil e exitosa com essas dificuldades.

Ressalta-se a sensibilidade e a habilidade de Nello ao compreender e considerar as lógicas de raciocínio e de ação de cada pessoa, em diferentes momentos e ocasiões 
DÁ PRA FAZER - PROBLEMATIZAÇÕES ACERCA DE ASPECTOS DA TEMÁTICA TRABALHO E EDUCAÇÃO ESCOLAR PARA PESSOAS COM DIVERSIDADE FUNCIONAL INTELECTUAL AGNES IARA DOMINGOS MORAES Y CLÁUDIO RODRIGUES DA SILVA

sociais, incentivando-as à assunção das diferentes tarefas e ao enfrentamento dos desafios, conforme as respectivas condições biopsicossociais.

Em outras palavras - fazendo inferências a partir de Oliveira (2008), ao discutir a questão das adequações curriculares de pequeno e grande portes para pessoas com «deficiência intelectual»-, pode-se inferir que Nello fez uma espécie de «adequação», isto é, personalizou as atividades, valorizando e destacando as potencialidades e respeitando os limites de cada pessoa, porém, sempre instigando-as a desafiar esses limites. Destaca-se que, comumente, Nello não as desautorizava nem subestimava a capacidade delas; assim não fazia as atividades por elas; no máximo, realizava algumas atividades com elas.

Além disso, Nello empenhou-se para não transformar as diferenças individuais em desigualdades sociais, incentivando um clima de auto-organização e apoio mútuo; em outras palavras, promoveu uma relação de cooperação não alienada. Os sócios mostraram-se capazes de, a partir das próprias lógicas de raciocínio, de tempo e de temporalidade, enfrentar criativamente situações adversas, tensas ou mesmo limítrofes.

O filme contribui para reflexões acerca, dentre outras temáticas, dos desafios implicados com a questão da inclusão das pessoas com diversidade funcional intelectual, principalmente no que se refere ao trabalho e à educação, em especial a escolar.

Várias das inciativas combatidas ou defendidas/implementadas por Nello são consoantes com apontamentos de Schalock e Verdugo (2007) sobre a questão da «calidad de vida» para pessoas com diversidade funcional intelectual, entre elas, Desarrollo personal, Autodeterminación, Relaciones interpersonales, Inclusión social, Derechos, Bienestar Emocional, Bienestar Físico e Bienestar Material.

Ressalta-se que, no Brasil, esse é um segmento de populações que historicamente foi - e, em certa medida, continua a ser - estigmatizado ou marginalizado em variadas áreas sociais (Jannuzzi, 1985; Mazzotta, 2001; Omote, 2013), em especial no que se refere a essas duas áreas que, dada a sua centralidade em sociedades modernas, têm repercussões em praticamente quase todas as instâncias da vida, tanto na esfera mais individual quanto na esfera mais coletiva.

Considerando-se, nessas sociedades, a importância do trabalho (Alves, 2oı; Antunes, I999) e da educação escolar (Noma e Czernisz, 20ı0; Souza, 20ıo) - no sentido lato desses termos - para o processo de socialização e de humanização, já que são elementos indispensáveis para a reprodução da vida, tanto na dimensão material quanto na simbólica, faz-se necessário aprofundar a problematização dessa polêmica temática, especialmente no que tange às pessoas com diversidade funcional intelectual. Esse segmento, em decorrência de políticas públicas (Brasil, I99I, 2008), vem registrando maior percentual de inserção, ainda, não raramente, incipiente e precária, em diferentes níveis da educação escolar, bem como em dados postos do mercado de trabalho ${ }^{4}$.

A questão do acesso, permanência, progressão nos estudos e, principalmente, da apropriação dos conhecimentos escolares torna-se ainda mais desafiadora em se tratando de pessoas com diversidade funcional intelectual residentes no campo (CAiAdo e MeletTi, 20II; Silva et al., 20I5; Torres et al., 20I5; Torres et al., 20I4). Ressalta-se que as populações residentes no campo foram e continuam a ser, com variações conforme as conjunturas e localidades, historicamente preteridas nas políticas educacionais (MORAES, 20I4). Ainda que, em decorrência da Constituição Federal de I988, sejam registrados alguns avanços em termos de direito à educação escolar para esse e outros segmentos, na atualidade várias dessas conquistas estão em franco risco de retrocessos, devido a alterações na legislação realizadas ou em vias de sê-lo no Brasil (Moraes e SiLVA, 20I8). 
DÁ PRA FAZER - PROBLEMATIZAÇÕES ACERCA DE ASPECTOS DA TEMÁTICA TRABALHO E EDUCAÇÃO ESCOLAR PARA PESSOAS COM DIVERSIDADE FUNCIONAL INTELECTUAL AGNES IARA DOMINGOS MORAES Y CLÁUDIO RODRIGUES DA SILVA

Lorenzo (2016: 15), ao tratar da «inserção» das pessoas com deficiência no mercado de trabalho, aponta que, no Brasil, $23,9 \%$ da população nacional apresentam algum tipo de diversidad funcional; desse total, conforme dados da Relação Anual de Informações Sociais (RAIS) de 20I3, «[...] menos de I\% (o,73\%) dos cidadãos com deficiência estavam inseridos no mercado formal de trabalho».

No entanto, se, por um lado, reconhece-se que a educação é necessária, por outro, coloca-se - sem pretensão de respondê-las - duas questões-chave para reflexão: I) Qual a concepção de educação propiciada, isto é, educar para quê? 2) Qual a concepção de trabalho reservada para pessoas com diversidade funcional intelectual? Essas questões são elementares, pois o trabalho e a educação, dependendo da visão de mundo subjacente a eles, podem ser fatores tanto de humanização e de emancipação quanto de embrutecimento e de alienação.

Quanto à educação escolar no Brasil, nas últimas décadas, houve uma ampliação significativa de matrículas desse segmento. Mas, o direito à matrícula, conforme ressaltado, não necessariamente implica a efetiva apropriação dos conhecimentos escolares (Moraes e Silva, 20I8).

Quanto ao trabalho, além do desemprego - que envolve as dimensões conjuntural e estrutural -, a inserção não acompanha proporcionalmente a inserção educacional, pois, enquanto à Educação Básica o acesso é franco, no mercado de trabalho a inserção ocorre predominantemente por força da legislação, isto é, por intermédio de cotas. Assim, essa inserção tende a ocorrer comumente em cargos mais básicos, o que pode ter diversos impactos na vida dessas pessoas, pois quanto mais básico o cargo, menor o salário, dada a meritocracia, que vincula escolarização, cargos, salários e empregabilidade. As premissas fundamentais do mercado de trabalho repercutem, em alguma medida, na educação escolar. Entre essas premissas, destacam-se a concorrência e a produtividade, que também podem impactar nas condições de inserção e permanência desse segmento em determinados empregos. Sem desconsiderar as contradições envolvidas, parece pertinente questionar a qualidade e a quantidade da inserção dessas pessoas na escola e no trabalho e possíveis desdobramentos. Uma questão-chave necessária é: em que condições e em que funções/cargos ocorre a inserção dessas pessoas - considerando-se, inclusive, as diversas especificidades contempladas na grande categoria denominada pessoas com diversidade funcional intelectual - no mercado de trabalho?

A título de considerações finais, destaca-se que, por um lado, políticas de inclusão social foram implementadas em decorrência inclusive de Convenções Internacionais, com participação de alguns organismos multilaterais. Por outro lado, em grande medida, avanços em termos de políticas públicas são conquistas decorrentes de lutas históricas de organizações ou movimentos sociais, principalmente de pessoas com diversidad funcional (Gohn, 20II; Moraes e Silva, 20I8).

Ressalta-se que, em especial na atualidade, há, ainda que arbitrariamente e com finalidades de seleção ou exclusão, uma relação entre níveis de educação escolar e acesso a determinados postos de trabalho, relação essa que também carece de problematização, dadas, como aponta Silva (2015), as possíveis relações com a ideologia da meritocracia. 
DÁ PRA FAZER - PROBLEMATIZAÇÕES ACERCA DE ASPECTOS DA TEMÁTICA TRABALHO E EDUCAÇÃO ESCOLAR PARA PESSOAS COM DIVERSIDADE FUNCIONAL INTELECTUAL AGNES IARA DOMINGOS MORAES Y CLÁUDIO RODRIGUES DA SILVA

Assim como há mobilizações pelo direito à educação inclusiva (Echeita e Domínguez Gutiérrez, 2oII), considera-se necessário, no Brasil, um maior acompanhamento e uma maior mobilização, em perspectivas críticas, em torno da inclusão laboral de pessoas com diversidad funcional.

Um desafio que se coloca é ampliar e aprofundar os debates acerca da questão do trabalho e da educação para o segmento em tela, com vistas a tensionar e a provocar mudanças em representações sociais equivocadas ou improcedentes, representações essas que, não raramente, de maneiras homogeneizadoras ou generalizantes, apresentam expectativas que subestimam a capacidade de aprendizagem e de trabalho de pessoas com diversidade funcional intelectual. Essas mudanças precisam ocorrer nas mais diversas áreas, envolvendo variados atores sociais, inclusive - sem pretensão de generalizações - as próprias pessoas com diversidade funcional intelectual e seus familiais, colegas de estudo ou de trabalho, educadores, empregadores, dentre outros segmentos sociais.

\section{Referências}

Alves, G. (20II) Trabalho, subjetividade e capitalismo manipulatório - O novo metabolismo social do trabalho e a precarização do homem que trabalha. Revista da RET Rede de Estudos do Trabalho, 4, I-3I.

Antunes, R. (I999) Os sentidos do trabalho: ensaio sobre a afirmação e a negação do trabalho. São Paulo: Boitempo.

Brasil (1988) Constituição da República Federativa do Brasil. Recuperado dia 8 de agosto de 20I6, de http://www.stf.jus.br/arquivo/cms/publicacaoLegislacaoAnotada/anexo/Completo.pdf.

Brasil (I99i) Lei n. 8.213, de 24 e julbo de I99I. Dispõe sobre os Planos de Benefícios da Previdência Social e dá outras providências. Recuperado dia 8 de janeiro de 20I6, de https:// www.planalto.gov.br/ccivil_03/leis/L82I3cons.htm.

Brasil (1996) Lei de Diretrizes e Bases da Educação Nacional n. ${ }^{\circ}$ 9.394. Estabelece as Diretrizes e Bases da Educação Nacional. Brasília: Ministério da Educação.

Brasil (2008) Ministério da Educação. Secretaria de Educação Especial. Política Nacional de Educação Especial na Perspectiva da Educação Inclusiva. Brasília: MEc/secadi.

Caiado, K. R. M. e Meletti, S. M. F. (2OII) Educação especial na educação do campo no Estado de São Paulo: uma interface a ser construída. In L. Bezerra Neto e M. C. S. Bezerra (org.) Educação para o campo em discussão: subsídios para o Programa Escola Ativa (pp. I71-185). São José, Brasil: Premier.

Chauveau, G. (1998) L'école du travail dans la pensée ouvrière. Ville École Intégration, II3, I58-I7I. Recuperado dia 8 de novembro de 20I6, de http://www2.cndp.fr/revuever/chauveauir3.pdf.

Echeita, G. e Domínguez Gutiérrez, A. B. (2OII) Educación inclusiva. Argumento, caminos y encrucijadas, Aula, Revista de Pedagogía de la Universidad de Salamanca, 17, 23-35.

Freitas, M. A. de S. (20I4) Estudantes com deficiência intelectual de jovens e adultos: interfaces no processo de escolarização. Dissertação (Mestrado em Educação Especial) Universidade Federal de São Carlos, Brasil.

Gohn, M. G. (20II) Movimentos sociais na contemporaneidade. Revista Brasileira de Educação, I6, 333-361.

Jannuzzi, G. (1985) A luta pela educação do deficiente mental no Brasil. São Paulo: Cortez: Autores Associados.

LoRENZO, S. M. (2016) Inserção de pessoas com deficiências no mercado formal de trabalho a partir da percepção dos profissionais de recursos bumanos das empresas. Dissertação (Mestrado em Educação). Universidade Estadual Paulista, Faculdade de Filosofia e Ciências, Brasil. 
DÁ PRA FAZER - PROBLEMATIZAÇÕES ACERCA DE ASPECTOS DA TEMÁTICA TRABALHO E EDUCAÇÃO ESCOLAR PARA PESSOAS COM DIVERSIDADE FUNCIONAL INTELECTUAL AGNES IARA DOMINGOS MORAES Y CLÁUDIO RODRIGUES DA SILVA

Manacorda, M. A. (1992) História da educação: da antigüidade aos nossos dias. São Paulo: Cortez.

Marques, P. (20Io) Cooperativas sociais de usuários da saúde mental: Dá pra fazer. Recuperado dia Io de dezembro de 20I6, de http://cursodepsicologiasetrem.blogspot.com.es/20Io/og/ no-contexto-da-reforma-do-sistema-de.html.

Mazzotta, M. J. S. (200I) Educação especial no Brasil história e políticas públicas. São Paulo: Cortez.

Moraes, A. I. D. (20I4) Ensino primário tipicamente rural no Estado de São Paulo: um estudo sobre as Granjas Escolares, os Grupos Escolares Rurais e as Escolas Tipicas Rurais (1933-1968). São Paulo: Cultura Acadêmica.

Moraes, A. I. D. e Silva, C. R. (20I8) Educação Especial na Perspectiva da Educação Inclusiva no Brasil: após quase três décadas... quais as perspectivas? In L. F. Leal e A. I. D. Moraes (org.) Literatura, leitura e escrita: interfaces. Porto Alegre, Brasil: Editora Fi; Tupã, Brasil: Editora Faculdades FACCAT, 2018.

Noma, A. K. e Czernisz, E. C. S. (20ı) Trabalho, educação e sociabilidade na transição do século xx para o xxi: o enfoque das políticas educacionais. In J. S. Souza e R. Araújo (org.) Trabalho, educação e sociabilidade (pp. 193-210). Maringá, Brasil: Praxis: Massoni.

Oliveira, A. A. S. (2008) Adequações curriculares na área de deficiência intelectual: algumas reflexões. In A. A. S. Oliveira, S. Омоте e R. M. Giroto (org.) Inclusão escolar: as contribuições da Educação Especial (pp. I29-154). São Paulo, Brasil: Cultura Acadêmica; Marília, Brasil: Fundepe Editora.

Омоте, S. (20I3) Atitudes sociais em relação a inclusão: estudos brasileiros. Revista Ibero-Americana de Estudos em Educação, 8, 639-649.

PleTsCh, M. D. (2010) Repensando a inclusão escolar: diretrizes políticas, práticas curriculares e deficiência intelectual. Rio de Janeiro: Nau \& Edur.

Rodríguez Díaz, S. e VÁsquez Ferreira, M. Á. (20io) Desde la discapacidad hacia la diversidad funcional. Un ejercicio de dis-normalización. Revista Internacional de Sociología, 68, 289-309.

Romañach, J. e Lobato, M. (2005) Diversidad funcional, nuevo término para la lucha por la dignidad en la diversidad del ser humano. Recuperado dia is de novembro de 2016, de http://www.asoc-ies.org/vidaindepen/docs/diversidad\%2ofuncional_vf.pdf.

SADE, R. M. S. (2017) Apresentação. In R. M. S. SADE (org.) Boas práticas: caminos e descaminos no processo de desinstitucionalização (pp. 7-9). Marília, Brasil: Oficina Universitária; São Paulo, Brasil: Cultura Acadêmica.

Santos, S. N. e Noro, A. (2013) O uso de filmes como recurso pedagógico no ensino da Neurofarmacologia. Interface, 17, 705-714.

Schalock, R. L. e Verdugo, M. Á. (2007) El concepto de calidad de vida en los servicios y apoyos para personas con discapacidad intelectual. Revista Española sobre Discapacidad Intelectual, 38, 2I-36.

SILVA, C. R. (20I4) Educação e trabalbo em movimentos sociais: princípios educativos transcendentes e comuns ao Movimento dos Trabalhadores Rurais Sem Terra (MST), aos socialistas utópicos owenistas e aos cartistas britânicos. Dissertação (Mestrado em Educação). Universidade Estadual Paulista, Faculdade de Filosofia e Ciências, Brasil.

Silva, C. R. (20I5) Nas ondas de uma rádio: a educação como panaceia no discurso de quem diz fazer um Brasil melhor. Espaço Acadêmico, i4, 30-40.

Silva, C. R. et al. (20I5) Fechamento de escolas e implicações para a educação dos povos do campo. In N. A. L. Sicca e A. DAvid (org.) Diálogos na educação básica: políticas, currículo e discurso (pp. 29-53). Curitiba, Brasil: CRV.

Souza, J. S. (20I0) Trabalho, educação e luta de classes na sociabilidade do capital. In J. S. Souza e R. Araújo (org.) Trabalho, educação e sociabilidade (pp. 133-157). Maringá, Brasil: Praxis: Massoni. 
DÁ PRA FAZER - PROBLEMATIZAÇÕES ACERCA DE ASPECTOS DA TEMÁTICA TRABALHO E EDUCAÇÃO ESCOLAR PARA PESSOAS COM DIVERSIDADE FUNCIONAL INTELECTUAL AGNES IARA DOMINGOS MORAES Y CLÁUDIO RODRIGUES DA SILVA

Torres, J. C. et al. (20I4) Escolas públicas no campo: retrospectiva e perspectivas em um contexto de projetos políticos em disputa. Revista Eletrônica de Educação, 8, 262-272.

Torres, J. C. et al. (2015) Educação inclusiva no projeto educacional do MST. Comunicações, 22, I49-I64.

\section{Filmografia}

Dá prafazer. Direção: Giulio Manfredonia. Intérpretes: Claudio Bisio; Anita Caprioli; Andrea Bosca; Giovanni Calcagno; Micheli de Virgilio; Carlo Giuseppe Gabardini; Pietro Ragusa; Giorgio Colangeli; Giuseppe Battiston e outros. Itália: Rizzoli Film, 2008 (Iı min.). 
